\title{
Mobile eye screenings for Hawaii's homeless: results and applications
}

This article was published in the following Dove Press journal:

Clinical Optometry

II August 2010

Number of times this article has been viewed

\section{Jason B Barnes' \\ Shawn S Barnes ${ }^{2}$ \\ Christian R Small ${ }^{2}$ \\ Clifton S Otto ${ }^{3}$ \\ Michael D Bennett ${ }^{3}$}

'John A Burns School of Medicine, University of Hawaii; ${ }^{2}$ Outbound Eye Health International, ${ }^{3}$ Retina Institute of Hawaii, Honolulu, Hawaii, USA
Correspondence: Shawn S Barnes 34I 4 Hardesty St C, Honolulu, HI, USA Tel + I 8082235966

Email barn2243@yahoo.com
Purpose: To describe the status and perceptions of ocular health in Oahu's homeless population in Hawaii.

Patients and methods: A total of 127 participants were included in this community-based cross-sectional study. Examinations included demographic history, near and far presenting visual acuity (PVA), autorefractometry, and nonmydriatic retinal photography. PVA was measured using the participants' current eyeglasses or contacts, or without correction if they did not use glasses. Visual disability was categorized as "legally blind" (20/200 or worse), "impaired vision" (20/40 to 20/150), or "not impaired" (better than 20/40). Refraction data were categorized using the eye with a greater absolute spherical equivalent. Hyperopia was defined as more than $0.5 \mathrm{D}$ of plus and myopia as more than $0.5 \mathrm{D}$ of minus. Astigmatism was defined as cylindrical values more than $0.50 \mathrm{D}$ of minus or $0.50 \mathrm{D}$ of plus.

Results: Of 127 participants, $60.5 \%$ were displeased with their vision, $48.8 \%$ did not know where to go to seek eye care, and $66.7 \%$ did not know where to go to seek corrective lenses. Self-reported diabetes $(17.1 \%)$ was significantly higher $(P<0.001)$ than that of the general population of Hawaii (7.5\%). Less than one-third of diabetic participants had ever been evaluated by an ophthalmologist. The prevalence of refractive error was comparable with national rates, with myopia, hyperopia, and astigmatism at $23.5 \%, 1.2 \%$, and $35.3 \%$, respectively. Presenting visual acuity was found to be impaired or blind in $19.5 \%$ of participants for near vision testing and $12.1 \%$ for distance vision. The rates of retinal pathology in participants were found to be $1.6 \%$ with diabetic retinopathy, $0.8 \%$ with retinal hypertension, $2.4 \%$ with epiretinal membrane, $4.0 \%$ with drusen, and 0.8 with nevus.

Conclusion: The homeless population of Oahu has a high dissatisfaction with vision, comparable rates of ocular pathology with national samples, and poor knowledge of eye care services. This suggests that mobile eye screening could provide an ideal setting for providing ocular health care to the homeless population, and has enormous potential for improving health care in this population.

Keywords: homeless, visual acuity, refractive error, retina, Hawaii

\section{Introduction}

The detrimental affects of poverty ${ }^{1}$ and homelessness ${ }^{2}$ have been well documented. The homeless have been shown to be at substantially greater risk for infectious disease, ${ }^{3}$ dental problems,${ }^{4}$ mental illness,${ }^{5}$ chronic obstructive pulmonary disease,${ }^{6}$ and cardiovascular disease. ${ }^{7}$ Health disparities seen in the homeless may be due to issues such as lack of mobility or financial means to access care, cultural or language barriers to following self-care instructions, and environmental conditions, such as harsh weather, risk of trauma, and lack of secure storage for medications. ${ }^{8}$ 
While a wealth of published information exists on health issues in the homeless, to our knowledge, few studies have specifically investigated ocular health in this vulnerable population. 9,10

The homeless population on the island of Oahu, Hawaii, is notoriously difficult to census. Between June 2006 and July 2007, 5066 individuals received shelter services from state-sponsored agencies. ${ }^{11}$ However, this is a gross underestimation of the homeless population, because it does not take into account a substantial number of homeless that live outside the shelter system, eg, in parks and on beaches. It has been estimated that the homeless represent $0.47 \%$ of Hawaii's population, the fourth highest nationwide rate. ${ }^{8}$ One factor contributing to this high rate is Hawaii's increasing cost of living. The median home price on Oahu has jumped from $\$ 158,600$ in 1985 , to $\$ 643,500$ in 2007 , an increase of over $400 \% .^{12}$

The real and perceived health of Oahu's homeless follows the national trend of disparity. Oahu's homeless have been shown to be hospitalized in acute care and psychiatric hospitals far more frequently than members of the general population $^{13}$ and, in a recent survey, nearly half of Oahu's homeless rated their health as fair to poor, compared with only $13 \%$ in Oahu's general population. ${ }^{8}$

Our goal in this study was to obtain baseline information about visual acuity and ocular pathology, perceptions of ocular health, and knowledge of treatment access in Oahu's homeless population.

\section{Material and methods}

This paper reports a prospective, community-based, crosssectional study of eye disease in homeless persons officially registered at three shelters on Oahu (Kaka'ako, Barber's Point, and Waianae). The Project Vision Van, a mobile eye screening unit operated by the Retina Institute of Hawaii, was dispatched to each site. Convenience sampling screenings were performed on board the van by three medical students and an optometry technician. A board-certified ophthalmologist (CSO) was on hand to supervise all screenings. A standardized protocol was employed to maximize the convenience sampling participation of shelter residents at each site. After arriving on site, Project Vision Van volunteers notified all shelter residents individually and described the nature of the screenings. Interpreters were employed to recruit and assist those with language barriers. The sample size included a total of 127 homeless participants. Participants volunteered to complete a survey asking about subjective perceptions of eye health, knowledge about where to access eye care, and past ocular medical history.

Examinations involved presenting near and far visual acuity using standard Snellen distance charts and Rosenbaum near vision cards, refraction using autorefractometry (Canon AutoRef R-22), and nonmydriatic retinal photography (Canon DGI nonmydriatic retinal camera with Canon Rebel XTI 10.2 digital back). Following the screenings, nonmydriatic, nonstereo, retinal photographs were evaluated and scored for pathology by a board-certified ophthalmologist (CSO). No discrimination was made between nonproliferative versus proliferative status of diabetic retinopathy.

Presenting visual acuity was measured using the participants' current eyeglasses or contacts, or without correction if they did not use glasses. Visual disability was categorized as "legally blind" (20/200 or worse), "impaired vision" (20/40-20/150), or "not impaired" (better than 20/40). Refraction data were categorized using spherical equivalents (sphere $+1 / 2$ cylinder [diopters]) from the eye with the greatest absolute value. Hyperopia was defined as more than $0.5 \mathrm{D}$ of plus and myopia as more than $0.5 \mathrm{D}$ of minus. Astigmatism was defined as cylindrical values more than $0.50 \mathrm{D}$ of minus or $0.50 \mathrm{D}$ of plus.

A two-tailed z-test was used for group comparison to determine $95 \%$ confidence intervals. The standard for statistical significance was defined as $P$ values $\leq 0.05$.

Screenings were approved by the Independent Review Board of the University of Hawaii and conducted in accordance with the guidelines of the Declaration of Helsinki. Written informed consent, in the participants' own language, was obtained from all study participants. For those under 18 years of age, written informed consent was obtained from the parents. All participants, regardless of screening findings, were encouraged to follow-up with an eye physician for routine care and were given a list of low-cost eye clinics in their respective communities. Those participants requiring further evaluation or treatment were referred to a local optometrist or ophthalmologist.

\section{Results \\ Population demographics}

Data were collected for a total of 127 participants from all three sites. Of these, 61 participants were male (47\%) and 68 were female $(53 \%)$. The mean age of participants was 35 years (median 37, range 7-68 years). The majority of participants were of mixed ethnic (cosmopolitan) background, with the largest group being of part-Hawaiian descent $(n=66,51 \%)$. 


\section{Access to care}

Questions regarding self-reported access to ophthalmologic care and individual's perceptions of their ocular health revealed that the majority of individuals $(60.5 \%)$ were dissatisfied with their vision, had trouble seeing near objects $(49.6 \%)$ or far objects (57.4\%), and did not know where to go to seek eye care or corrective lenses ( $48.8 \%$ and $66.7 \%$, respectively). Of those who responded to an open-ended question on where to seek eye care, the most common responses were "doctor", "eye doctor", or a local "free health center". Table 1 shows the results of questions regarding self-reported health perceptions and access to ophthalmologic care among the homeless.

\section{Diabetes and eye care}

Diabetes in Hawaii's general population is estimated to be $7.5 \% .{ }^{14}$ When asked if "a doctor had ever diagnosed" participants with diabetes, the self-reported prevalence of diabetes in our study population was significantly higher than this $(17.1 \%, P<0.001)$. In addition, less than one-third of participants with self-reported diabetes had ever been evaluated by an ophthalmologist. This is in stark contrast $(P<0.0001)$ to the care received by Hawaii's general population of diabetics,

Table I Ocular health perceptions and access to care of the total sample population $(n=127)$

\begin{tabular}{lll}
\hline & $\begin{array}{l}\text { Number } \\
\text { (n) }\end{array}$ & $\begin{array}{l}\text { Percentage } \\
\text { (\%) }\end{array}$ \\
\hline $\begin{array}{l}\text { When was the last time your eyes were } \\
\text { examined by a doctor? }\end{array}$ & \\
$<$ I year & 29 & 22.5 \\
I-5 years & 47 & 36.4 \\
5+ years & 22 & 17.1 \\
Never & 31 & 24.0 \\
Have you ever had corrected vision & & \\
(glasses or contacts)? & & \\
No & 71 & 55.0 \\
$\begin{array}{l}\text { Do you have trouble seeing near objects? } \\
\text { Yes }\end{array}$ & 64 & 49.6 \\
$\begin{array}{l}\text { Do you have trouble seeing far objects? } \\
\text { Yes }\end{array}$ & 74 & 57.4 \\
If you had vision problems, where & & \\
would you go for help? & & \\
Specific place (doctor or clinic) & 66 & 51.2 \\
I don't know & 63 & 48.8 \\
If you ever needed a pair of glasses or & & \\
contacts, where would you get these? & & \\
Specific place (doctor or clinic) & 43 & 33.3 \\
I don't know & 86 & 66.7 \\
Have you ever been diagnosed with & & \\
an eye disease? & & \\
Yes & & \\
\hline
\end{tabular}

$81.6 \%$ of whom had received a dilated eye examination within the past year. ${ }^{14}$

\section{Presenting visual acuity}

Results for near and far presenting visual acuity (PVA) are reported in Table 2 and the Figure 1. Each participant was tested with their current spectacles or contacts. Only nine participants (7.3\%) had any correction for far vision and only one participant $(0.8 \%)$ had correction for near vision. This is significant, because the rate of vision impairment found for both near and far vision was $19.5 \%$ and $12.1 \%$, respectively.

\section{Refractive error}

No statistical significance was found in the prevalence of myopia, hyperopia, and astigmatism between our study population and the 1999-2004 National Health and Nutrition Examination Survey, a nationally representative sample in the US ${ }^{15}$ (Table 3).

\section{Retinal pathology}

Retinal pathology is reported in Table 4. Of the abnormal findings found on review of retinal photography, three were diagnosed as urgent cases. These persons were immediately referred to an ophthalmologist for evaluation and treatment.

\section{Discussion}

Although we report a trend of better visual acuity in the homeless and lower rates of myopia/hyperopia, these trends are not statistically significant when compared with a national sample. ${ }^{15}$ This is in contrast with previous vision studies in the homeless that have found significantly higher rates of visual impairment. ${ }^{9,10}$ This disparity may be an interesting avenue of future research. While this disparity may be due to low sample size, the unique ethnic makeup of Hawaii may play a role. Retinal pathology was found to mirror crude national rates of prevalence.

Table 2 Presenting visual acuity, and near and far vision for all ages

\begin{tabular}{|c|c|c|}
\hline & $\begin{array}{l}\text { Number } \\
\text { (n) }\end{array}$ & $\begin{array}{l}\text { Percentage } \\
\text { (\%) }\end{array}$ \\
\hline \multicolumn{3}{|l|}{$\begin{array}{l}\text { Classification of visual impairment } \\
\text { based on nearpresenting visual acuity }\end{array}$} \\
\hline Not impaired ( $20 / 40$ or better in either eye) & 100 & 80.5 \\
\hline Impaired vision (20/50-20//00 in either eye) & 18 & 14.6 \\
\hline Blind ( $20 / 200$ or worse in either eye) & 6 & 4.9 \\
\hline \multicolumn{3}{|l|}{$\begin{array}{l}\text { Classification of visual impairment based } \\
\text { on farpresenting visual acuity }\end{array}$} \\
\hline Not impaired & 109 & 87.9 \\
\hline Impaired vision & 12 & 9.7 \\
\hline Blind & 3 & 2.4 \\
\hline
\end{tabular}




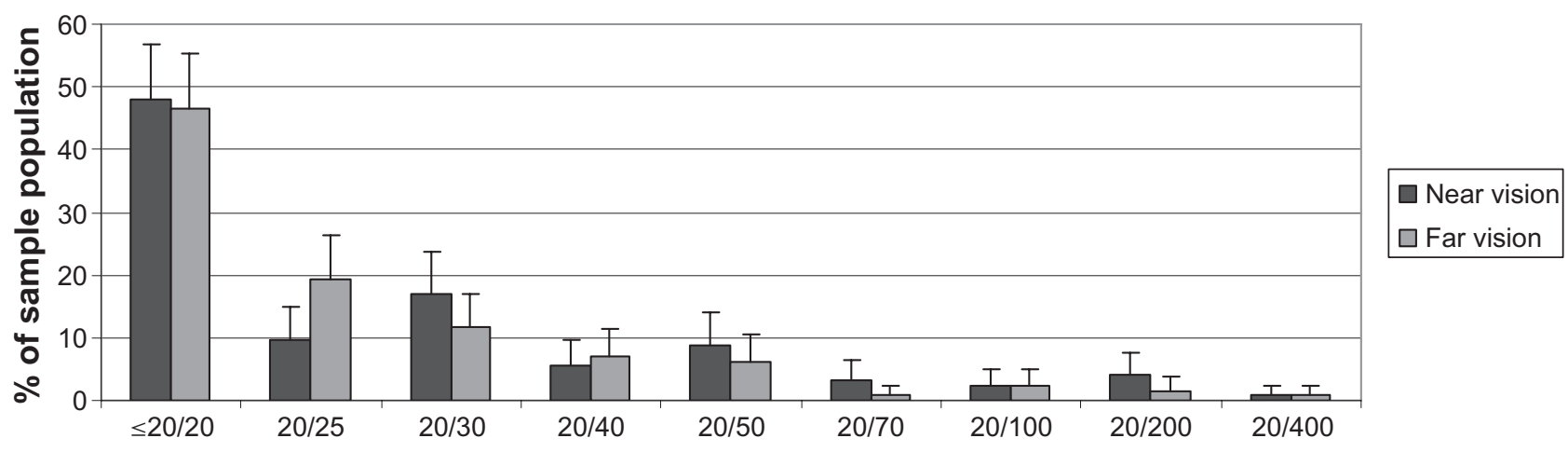

Figure I Presenting near and far visual acuity in the study population of Oahu's homeless with $95 \%$ confidence intervals.

Table 3 Prevalence of refractive error in the homeless, and in the 1999-2004 National Health and Nutrition Examination Survey (NHANES), in participants 18 years and older

\begin{tabular}{lll}
\hline & Homeless & NHANES \\
& $(\%)$ & $(\%)$ \\
\hline Myopia* & 23.5 & 33.1 \\
Hyperopia ** & 1.2 & 3.6 \\
Astigmatism*** & 35.3 & 36.2 \\
\hline
\end{tabular}

Notes: $* P$ value $=0.079 ; * * P$ value $=0.366 ; * * * P$ value $=0.953$.

Previous literature has shown that $77 \%$ of Oahu's homeless have health insurance coverage. ${ }^{8}$ Our data suggest that this population is not utilizing their coverage for eye care. Over $40 \%$ of our respondents reported not having had their eyes examined within the last five years. Alarmingly, nearly $70 \%$ of those with self-reported diabetes have never been evaluated by an eye doctor.

Our data suggest that one reason for this underutilization may simply be that the homeless population does not know where to go for care. Over half of our respondents did not know where to go to receive eye care, while two-thirds did not know where to obtain corrective lenses. Other factors affecting health care access by the homeless include lack of transportation, financial resources, and secure storage, along with the social stigma felt by a homeless person visiting an office not accustomed to treating this disadvantaged group. In addition, there is a pronounced lack of eye care services targeted to this surprisingly well-insured population. Perhaps mobile eye screenings may be a method of bridging this gap.

Table 4 Prevalence of retinal pathology via fundoscopy $(n=124)$

\begin{tabular}{llllll}
\hline & DR & Hypertension & ERM & Drusen & Nevus \\
\hline Number & 2 & $\mathrm{I}$ & 3 & 5 & $\mathrm{I}$ \\
Percentage & 1.6 & 0.8 & 2.4 & 4.0 & 0.8 \\
\hline
\end{tabular}

Abbreviations: DR, diabetic retinopathy, ERM, epiretinal membrane.
We found that poor knowledge of available eye care services for the homeless is a major barrier to routine eye examinations and potential treatment. Furthermore, despite adequate insurance coverage, the relatively low usage of traditional ophthalmologic services available suggests that additional measures could help facilitate access and usage of eye care and improve vision in this population. While this study is a convenience sample of relatively low sample size, and is not a statistical representation of Oahu's homeless population, the Project Vision Van provided an ideal setting for ocular screenings in homeless populations, and could be applied for subsequent larger epidemiologic analysis. The free examinations and the ability to bring the screenings directly to the study population made it possible to screen a large number of participants over a short period of time. Given this, mobile eye screenings have enormous potential for improving health care in homeless populations. For example, mobile eye screenings have been shown to be an effective outreach method of ophthalmology care in areas such as Africa, ${ }^{17-19}$ the United Kingdom, ${ }^{20}$ Australia, ${ }^{21}$ Costa Rica, ${ }^{22}$ and Los Angeles. ${ }^{10}$ Additional resources need to be mobilized at the local and national level to insure that such vision screenings are available to our growing homeless population.

\section{Acknowledgments}

This research was supported by the University of Hawaii Maguire Fund. We would like to thank Project Vision and the Hawaii Vision Project Foundation, David Ng, DeLara Julian, and the Homeless Outreach and Medical Education program. David Waters, Connie Cox, and George Nardin provided invaluable insights. A special thanks to Paul Morton, Amelia Fong, Iris Kim, Brad Kamitaki, Kate Pettigrew, Luke Dunklee, and the residents of the Next Step Shelter in Kaka'ako, Paiolo Kaiaulu shelter in Waianae, and Onemalu shelter at Barber's Point. 


\section{Disclosure}

The authors report no conflicts of interest in this work.

\section{References}

1. Farmer P. Pathologies of Power: Health, Human Rights, and the New War on the Poor. Berkeley, CA: University of California Press; 2003.

2. Martens WH. A review of physical and mental health in homeless persons. Public Health Rev. 2001;29:13-33.

3. Badiaga S, Raoult D, Brouqui P. Preventing and controlling emerging and reemerging transmissible diseases in the homeless. Emerg Infect Dis. 2008;14:1353-1359.

4. King TB, Gibson G. Oral health needs and access to dental care of homeless adults in the United States: A review. Spec Care Dentist. 2003;23:143-147.

5. Fazel S, Khosla V, Doll H, Geddes J. The prevalence of mental disorders among the homeless in Western countries: Systematic review and metaregression analysis. PLoS Med. 2008;5:e225.

6. Snyder LD, Eisner MD. Obstructive lung disease among the urban homeless. Chest. 2004;125:1719-1725.

7. Diez-Roux AV, Northridge ME, Morabia A. Prevalence and social correlates of cardiovascular disease risk factors in Harlem. Am J Public Health. 1999;89:302-307.

8. Withy KM, Amoa F, Andaya JM, et al. Health care needs of the homeless of Oahu. Hawaii Med J. 2008;67:213-216.

9. Pitz S, Kramanna C, Krummenauerb F, et al. Is homelessness a risk factor for eye disease? Results of a German screening study. Ophthalmologica. 2005;219:345-349.

10. Ho JH, Chang RJ, Wheeler NC, Lee DA. Ophthalmic disorders among the homeless and nonhomeless in Los Angeles. J Am Optom Assoc. 1997;68:567-573.
11. Yuan S, Kole S, Yuen S. Homeless Service Utilitization Report: Hawaii 2008. University of Hawaii; Center on the Family; 2008:1-15.

12. Honolulu Board of Realtors. Annual residential resales data for Oahu. Available at: http://www.hicentral.com/pdfs/annsales.pdf. Accessed Dec 20, 2008.

13. Martell JV, Seitz RS, Harada JK, Kobayashi J, Sasaki VK, Wong C. Hospitalization in an urban homeless population: The Honolulu Urban Homeless Project. Ann Intern Med. 1992;116:299-303.

14. Centers for Disease Control and Prevention. National Center for Chronic Disease Prevention and Health Promotion. Diabetes Data and Trends. Available at: http://apps.nccd.cdc.gov/DDTSTRS. Accessed Feb 7 , 2009.

15. Vitale $\mathrm{S}$, Cotch MF, Sperduto RD. Prevalence of visual impairment in the United States. JAMA. 2006;295:2158-2163.

16. Chui J, Di Girolamo N, Wakefield D, Coroneo MT. The pathogenesis of pterygium: Current concepts and their therapeutic implications. Ocul Surf. 2008;6:24-43.

17. Yeung I, Wiafe B. An outreach eye care programme, Zambia. Community Eye Health. 2002;15:13-14.

18. McManus M. Mobile eye units in the fight against eye disease in east Africa. J Ophthalmic Nurs Technol. 1993;12:19-21.

19. Hill JC. Mobile eye-care teams and rural ophthalmology. S Afr Med J. 1984;66:531-535.

20. Leese GP, Ahmed S, Newton RT. Use of mobile screening unit for diabetic retinopathy in rural and urban areas. BMJ. 1993;306:187-189.

21. Harper CA, Livingston PM, Wood C. Screening for diabetic retinopathy using a non-mydriatic retinal camera in rural Victoria. Aust $N Z J$ Ophthalmol. 1998;26:117-121.

22. Ruggeiro CP, Gloyd S. Evaluation of vision services delivered by a mobile eye clinic in Costa Rica. Optom Vis Sci. 1995;72:241-248.

\section{Clinical Optometry}

\section{Publish your work in this journal}

Clinical Optometry is an international, peer-reviewed, open access journal publishing original research, basic science, clinical and epidemiological studies, reviews and evaluations on clinical optometry. All aspects of patient care are addressed within the journal as well as the practice of optometry including economic and business analyses. Basic and clinical

\section{Dovepress}

research papers are published that cover all aspects of optics, refraction and its application to the theory and practice of optometry. The manuscript management system is completely online and includes a very quick and fair peer-review system, which is all easy to use. Visit http://www.dovepress. com/testimonials.php to read real quotes from published authors. 